\title{
Stress Profiling in Cold-Spray Coatings by Different Experimental Techniques: Neutron Diffraction, X-Ray Diffraction and Slitting Method
}

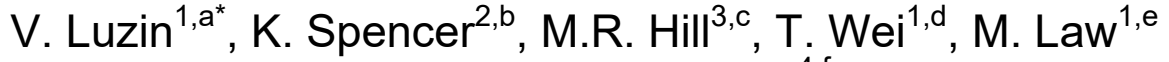 \\ and T. Gnäupel-Herold ${ }^{4, f}$ \\ ${ }^{1}$ Australian Nuclear Science \& Technology Organisation, Lucas Heights, NSW 2234, Australia \\ ${ }^{2}$ School of Mechanical and Mining Engineering, The University of Queensland, QLD 4072, \\ Australia \\ ${ }^{3}$ Department of Mechanical and Aerospace Engineering, University of California, Davis, CA \\ 95616, USA \\ ${ }^{4}$ NIST Center for Neutron Research, National Institute of Standards and Technology, \\ Gaithersburg, MD 20899, USA \\ avladimir.luzin@ansto.gov.au, bkrspencer@gmail.com, cmrhill@ucdavis.edu, \\ dtao.wei@ansto.gov.au, ${ }^{\mathrm{e}}$ michael.law@ ansto.gov.au, ${ }^{\mathrm{f}}$ thomas.gnaeupel-herold@nist.gov
}

\section{Keywords: Residual Stress, Coatings, Cold Spray, Neutron Diffraction}

Abstract. The residual stress profiles in $\mathrm{Cu}$ and $\mathrm{Al}$ coatings sprayed using kinetic metallization to thickness of $\sim 2 \mathrm{~mm}$ have been studied. Due to specific parameters of the cold-spray process and particular combination of materials, coatings and substrates, the residual stresses are low with magnitudes of the order of a few tens of MPa. This poses challenges on accuracy and resolution when measuring through-thickness stress distributions. Three experimental techniques - neutron diffraction, X-ray diffraction and a slitting method - were used to measure throughthickness stress distributions in the substrate-coating systems. All three techniques demonstrated acceptable accuracy and resolutions suitable for analyzing stress profiles. Advantages and disadvantages of each technique are discussed.

\section{Introduction}

Coatings of many different materials and thicknesses find their use in various surface enhancement applications such as wear resistance, corrosion protection, insulation, etc. They can be deposited on surfaces of engineering components by a number of techniques including thermal and cold spray. These techniques are energetic processes that generally induce residual stresses either through thermal effects or kinetic impact. The residual stresses can be detrimental for the coating's mechanical integrity or functional performance, therefore stress control or mitigation is usually required.

For coatings with thickness of a few millimeters, several stress measurement techniques can be used. Neutron diffraction stress measurement has proven to be a useful method for thick [1] and thin coatings [2] owing to some advantages: It is non-destructive and it can provide the required high resolution (down to $0.2 \mathrm{~mm}$ ); No special sample preparation (e.g. cutting and polishing, as for X-rays) is required: Measurements can be done in a reasonable time (minutes per datum) and with high accuracy (uncertainty can be better than $5 \mathrm{MPa}$ ). The slitting method, despite it being a destructive technique, has also been proven to be an efficient method for stress measurements due to the high spatial resolution and accuracy it provides [3]. The laboratory Xray diffraction technique is not commonly used for through-thickness stress measurement in coatings, nor is it associated with high spatial resolution as required for the investigation of 
coatings. Some advances in the technique [4] and demonstration of its ability in application to thin $(\sim 1 \mathrm{~mm})$ metal sheets [5] open opportunities for a new application of this technique. Since the laboratory X-ray technique is most accessible, it gives certain advantages to this technique.

In this work we report on an experimental study of the residual stress analysis in cold-spray coatings made with the three techniques mentioned.

\section{Sample production}

Two coatings were sprayed using the kinetic metallization (KM) cold-spray technique with a simple convergent barrel nozzle at a nozzle standoff distance of $12 \mathrm{~mm}$ and a nozzle traverse speed of $50 \mathrm{~mm} / \mathrm{s}$. The gas temperature-pressure conditions, optimized for deposition efficiency and reported in Table 1 were also used to estimate the exit velocity of the particles.

The deposition of powder on flat copper coupons $\left(30 \times 30 \mathrm{~mm}^{2}, 3 \mathrm{~mm}\right.$ thickness) resulted in coatings with a thickness of $\approx 2.1 \mathrm{~mm}$ for both materials.

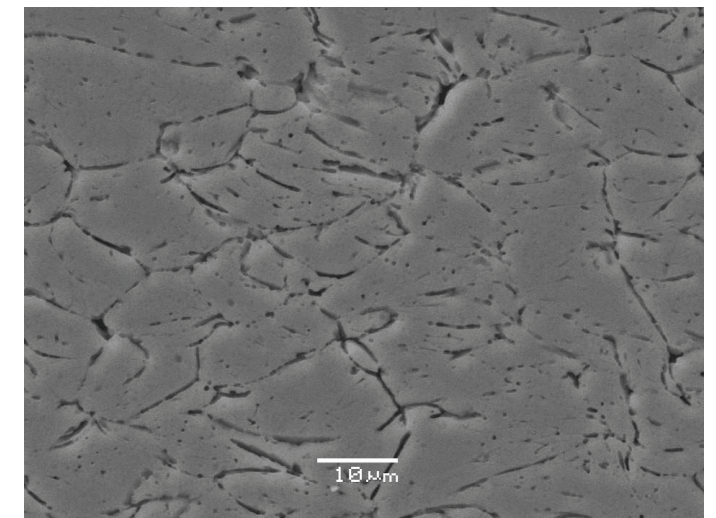

Fig. 1: Microstructure of the Al coating.

Table 1. Sample spraying conditions and parameters.

\begin{tabular}{|c|c|c|c|c|c|}
\hline $\begin{array}{c}\text { Powder } \\
\text { Material }\end{array}$ & $\begin{array}{c}\text { Average } \\
\text { Particle } \\
\text { Size }[\mu \mathrm{m}]\end{array}$ & $\begin{array}{c}\text { Driving } \\
\text { Pressure } \\
{[\mathrm{kPa}]}\end{array}$ & $\begin{array}{c}\text { Nozzle } \\
\text { Temperature } \\
{\left[{ }^{\circ} \mathrm{C}\right]}\end{array}$ & $\begin{array}{c}\text { Powder } \\
\text { Feed Rate } \\
{[\mathrm{g} / \mathrm{min}]}\end{array}$ & $\begin{array}{c}\text { Estimated } \\
\text { Particle Exit } \\
\text { Velocity }[\mathrm{m} / \mathrm{s}]\end{array}$ \\
\hline $\mathrm{Al}$ & 15 & 620 & 140 & 15 & 585 \\
\hline $\mathrm{Cu}$ & 6 & 620 & 200 & 15 & 645 \\
\hline
\end{tabular}

Sample characterization

(i) For measurements of the Young's modulus, rectangular specimens were extracted from the bulk of the coating with approximate dimensions $30 \times 5 \times 2 \mathrm{~mm}^{3}$. The Young's modulus E was determined using the impulse excitation technique (ASTM standard E1876) through acoustic measurements of the normal frequency and the sample dimensions. The accuracy of this method was better than $1 \%$. The same samples were used for density $\rho$ measurements (Table 2 ).

(ii) In order to determine the phase composition, the full neutron diffraction patterns were measured (using the very same bar samples used for the Young's modulus measurement) in the $2 \theta$ range of $10^{\circ}-160^{\circ}$ at a wavelength of $1.62 \AA$ using high-resolution powder diffractometer ECHIDNA at the ANSTO OPAL research reactor [6]. The volume fractions of the phases were extracted through a refinement procedure (Table 2 ).

Table 2. Coating's material characterization: Young's modulus, density and phase composition.

\begin{tabular}{|l|l|l|l|l|l|}
\hline $\mathrm{ID}$ & $\mathrm{E}[\mathrm{GPa}]$ & \% of bulk & $\rho\left[\mathrm{g} / \mathrm{mm}^{3}\right]$ & \% of bulk & Phase composition, vol \% \\
\hline $\mathrm{Al}$ & $49.4 \pm 0.2$ & $69.6 \pm 0.3$ & $2.528 \pm 0.016$ & $93.6 \pm 0.6$ & $\mathrm{Al} 100 \%$ \\
\hline $\mathrm{Cu}$ & $104.0 \pm 0.5$ & $83.9 \pm 0.6$ & $8.670 \pm 0.044$ & $98.5 \pm 0.5$ & $\mathrm{Cu} 95 \%+\mathrm{Cu}_{2} \mathrm{O} 5 \%$ \\
\hline
\end{tabular}

\section{Neutron residual stress measurements}

The neutron diffraction residual stresses measurements were carried out at the NIST Center for Neutron Research using the BT8 residual stress diffractometer [7]. In correlation to the sample thicknesses a $0.5 \times 0.5 \times 18 \mathrm{~mm}^{3}$ sized gauge volume was used. For the most optimal definition of the gauge volume a $90^{\circ}\left(2 \theta_{\mathrm{B}} \sim 90^{\circ}\right)$ diffraction geometry was employed by setting the take-off angle $2 \theta_{\mathrm{M}}$ of the $\mathrm{Si}(311)$ monochromator and the wavelength $\lambda$ accordingly (Table 3 ). Through- 
thickness measurements were done in locations within the substrate and coating with $0.3 \mathrm{~mm}$ spacing between points. For each measurement point d-spacings were measured in the two principal directions, normal to the surface and in-plane. The d-spacings of the (311) reflections were measured with sufficient statistics to provide at least $5 \times 10^{-5}$ uncertainty in the strain. Since $\mathrm{Cu}$ is a stronger neutron scatterer, 10 minutes per measurement point $(\mathrm{t})$ were adequate for $\mathrm{Cu}$, while 90 minutes were required for Al. Assuming a balanced biaxial plane-stress state, the stress values were calculated according to the procedure [1] from the measured d-spacings and the diffraction elastic constants estimated by the self-consistent Kröner method [9] (Table 3).

Table 3. Neutron instrument setting and material constants for the measured reflections.

\begin{tabular}{|l|l|l|l|l|l|l|l|}
\hline & $\mathrm{d}[\AA]$ & $2 \theta_{\mathrm{M}}$ & $\lambda[\AA]$ & $2 \theta_{\mathrm{B}}$ & $\mathrm{S}_{1}\left[\mathrm{TPa}^{-1}\right]$ & $1 / 2 \mathrm{~S}_{2}\left[\mathrm{TPa}^{-1}\right]$ & $\mathrm{t}[\mathrm{min}]$ \\
\hline $\mathrm{Cu}(311)$ & 1.10 & $70.0^{\circ}$ & 1.55 & $89.7^{\circ}$ & -3.38 & 12.58 & 10 \\
\hline $\mathrm{Al}(311)$ & 1.22 & $79.8^{\circ}$ & 1.72 & $89.5^{\circ}$ & -5.16 & 19.57 & 90 \\
\hline
\end{tabular}

\section{X-ray diffraction measurements}

On completion of the neutron diffraction measurements, the samples were cut in halves and the surface of the cross-sectional cut investigated with X-ray measurements (after appropriate surface preparation). The measurement technique used in the high spatial resolution measurements was described previously [4]. It utilizes a very narrow vertical beam, $0.05 \mathrm{~mm}$ in our case, a combination of $\Omega$ - and $\Psi$-angles, as well as sample rotation applied in such a way that ensures that the X-ray beam projection remains parallel to the surface/interface, therefore representing the same through-thickness depth, and does not exceed the desired spatial resolution, $0.1 \mathrm{~mm}$ in our case.

The $\mathrm{Cu}$-tube $\mathrm{K}-\alpha$ radiation was used to measure the $\mathrm{Cu}(420)$ and $\mathrm{Al}(511 / 333)$ reflections. Although measurement time with such a small beam is an order of magnitude longer $(\mathrm{t}=120$ seconds for each orientation), many through-thickness locations could be measured in the available beamtime. The experimental details of the X-ray measurements are summarised in Table 4.

The primary interest was on locations immediately adjacent to the interface, thus posing a challenge for the neutron technique. Thus, 6 points in each coating were measured in steps of 0.1 $\mathrm{mm}$ with the first point located $0.1 \mathrm{~mm}$ away from the interface. The average uncertainty of Xray stress values was better than $5 \mathrm{MPa}$, a prerequisite to resolve subtle stress variations.

An attempt was also made to measure stresses in the $\mathrm{Cu}$ substrate, but due to the large grains, statistical variations were too great to provide a reliable result notwithstanding measurements taken for two $\mathrm{Cu}$ reflections, $\mathrm{Cu}(420)$ and $\mathrm{Cu}(331)$ and used in combination. Therefore, this data was omitted from the publication.

Table 4. X-ray instrument setting and material constants for the measured reflections.

\begin{tabular}{|l|l|l|l|l|l|l|l|}
\hline & $\mathrm{d}[\AA]$ & $\mathrm{Tube}$ & $\lambda[\AA]$ & $2 \theta_{\mathrm{B}}$ & $\mathrm{S}_{1}\left[\mathrm{TPa}^{-1}\right]$ & $1 / 2 \mathrm{~S}_{2}\left[\mathrm{TPa}^{-1}\right]$ & $\mathrm{t}[\mathrm{sec}]$ \\
\hline $\mathrm{Cu}(420)$ & 0.8061 & $\mathrm{Cu}$ & 1.54433 & $145^{\circ}$ & -2.87 & 11.01 & 120 \\
\hline $\mathrm{Al}(511 / 333)$ & 0.7793 & $\mathrm{Cu}$ & 1.54433 & $163^{\circ}$ & -5.15 & 19.69 & 120 \\
\hline
\end{tabular}

\section{Slitting measurements}

For the slitting method stress measurements [3], $5 \mathrm{~mm}$ thick slices were cut from each of the Xray samples to have $5 \times 5 \times 30 \mathrm{~mm}^{3}$ bars available for these tests. (Through-thickness dimension size of $5.3 \mathrm{~mm}$ is composed of the $3.2 \mathrm{~mm}$ thick $\mathrm{Cu}$ substrate and a $2.1 \mathrm{~mm}$ thick coating). A strain gauge attached to the surface opposite to the coated surface was used to measure strain changes when a slit was cut through the sample thickness by wire EDM. Cut depth increments 
were $0.1-0.2 \mathrm{~mm}$, with a final cut depth of about $4.5 \mathrm{~mm}$ from the top surface. This allowed for reconstruction of the stresses in the coatings and most of the substrate thicknesses.

The reconstruction of the stress profiles from the strain gauge data was done in two different ways: The unit-pulse analysis approach using a Tikhonov regularisation to reconstruct stress profiles of different degrees of smoothness and statistical robustness; Eigenstrain analysis approach where the stress profile solution is sought within a priori determined class of functions (e.g. polynomial of $\mathrm{n}^{\text {th }}$ order) as a best fit to the experimental data. A comparison of the two approaches is given if Fig. 2 for the $\mathrm{Cu} / \mathrm{Cu}$ system. The second approach (eigenstrain, order $=1$ ) in the case of sprayed coating has certain advantages since it is known that: (i) the stress profile in the substrate is a linear function (elastic bending response to bring about force and bending moment balances); (ii) the stress profile in the coating typically is a very smooth function, very close to a linear function (as demonstrated below by modelling results). In fact, this type of solution is the only one that can provide a reasonable result in the most difficult case, i.e. the $\mathrm{Al} / \mathrm{Cu}$ system.

\section{FEM modelling}
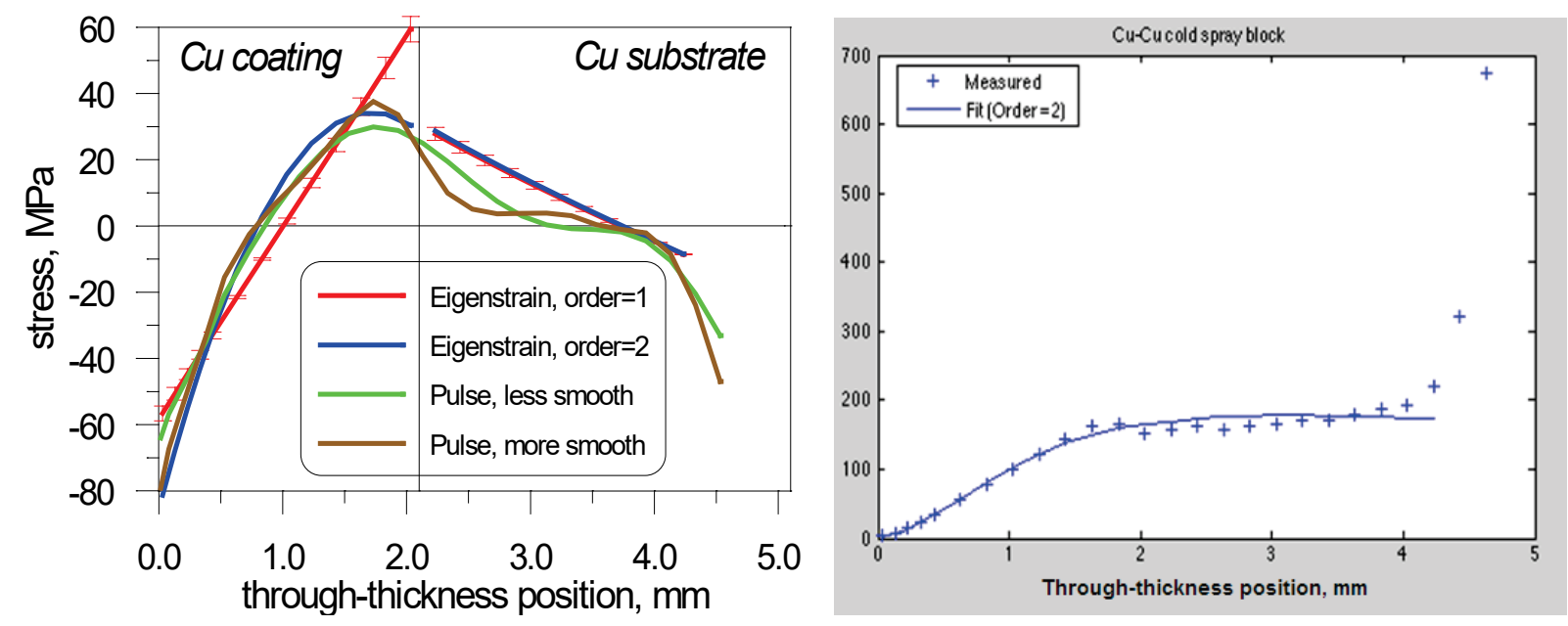

Fig. 2: Slitting method analysis of the Cu/Cu system: (left) several solutions of the reconstructed stress and (right) a corresponding strain function ( $\mu$ strain vertical axis) fitting the strain gauge experimental data for one of the solutions. The results are provided in the coordinate system of the EDM cut: zero point corresponds to the top coating surface.

The most critical part of the stress analysis in coatings is the geometrical conditions of the investigated samples and the relationship between measured stresses. In reality, the measured strains/stresses are not exactly the same (Fig. 3): (i) The neutron measurements were done in the central part of the sample, away from the edges, ensuring that the original equi-biaxial (typical for most coatings) stress state is measured; (ii) For the X-ray technique measurements are made on a cut, so the stress state is not equi-biaxial anymore and the normal stress component is eliminated by the presence of a free surface. One in-plane component remains, but may be altered by the cut; (iii) For convenience of the slitting method, the original sample was altered even further. The second cut to produce a $5 \mathrm{~mm}$ bar further reduces constraints from the other parts of the half-sample, thus changing the stress state again.

To address the issue of the different sample geometries and relationships between stress states the Chill modelling approach [9] was applied on a generalized bi-metal two-layer plate sample to emulate the coating/substrate system. The system was $5 \mathrm{~mm}$ thick $\mathrm{Al}(\mathrm{E}=70 \mathrm{GPa})$ and $3 \mathrm{~mm}$ thick steel $(\mathrm{E}=210 \mathrm{GPa})$ with plate dimensions $100 \times 100 \mathrm{~mm}^{2}$. Instead of a stress profile 
generated by a deposition process, a stress profile was induced here thermally through a combination of different coefficients of thermal expansion and temperature increments.

Using ABAQUS, the two consecutive cuts were simulated by tracing the stress relaxations and stress profiles at each step. The results of the simulation are given in Fig. 4. Although some geometry effects are visible in the simulation as distortions of the stress profile from the ideal (theoretically linear), the general trend of the stress distribution demonstrates that a stress relaxation effect is observable, but not at a significant level. Some $80-90 \%$ of the original stress magnitude is preserved in the bar or edge sample. Although, some corrections (a factor) can be applied to account for the partial stress relaxation of the remaining in-plane component, but in our case this effect was considered negligible.

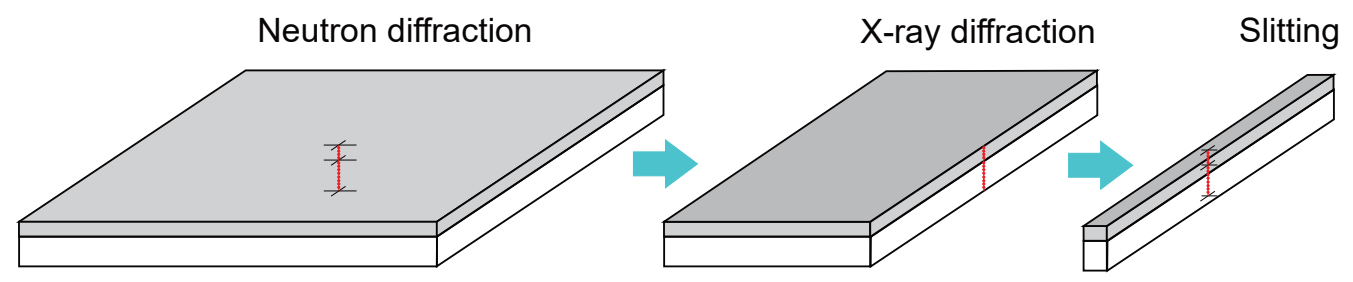

Fig. 3: Three different sample geometries used for the investigation with the three techniques.


Fig. 4: Relaxation of the stress on the sample edge (left) and in the thin bar (right) in comparison with the stress in the middle of the uncut sample.

\section{Results and discussion}

The results of the three experimental methods are combined in Fig. 5. Overall, all three methods demonstrated an ability to resolve the stresses with good accuracy, $<5-10 \mathrm{MPa}$, even in the case of very subtle stress distribution in the $\mathrm{Al} / \mathrm{Cu}$ system. It is therefore confirmed that any of the techniques is suitable for stress measurements in coatings.

While neutrons and X-rays are in very good agreement, the slitting methods results have some visible deviation from the diffraction results, as is seen most vividly in the $\mathrm{Cu} / \mathrm{Cu}$ system. Upon reviewing, there are at least two objective reasons for results of the slitting method to differ. Both of them are linked to the fact that the top surface is not smooth, but exhibits a significant variation of $\pm 0.4 \mathrm{~mm}$ from the average, as measured from minimum and maximum values (Fig. 5). Due to this, depending on the exact location of the EDM cut, the effective coating thickness can vary within a range, and strain relaxation readings will be sensitive to this effect. Secondly, for the stress reconstruction procedure, the coating and substrate thicknesses are parameters of the elastic model and therefore, if average (vs local) thickness is used, this will also impact the final stress values. 

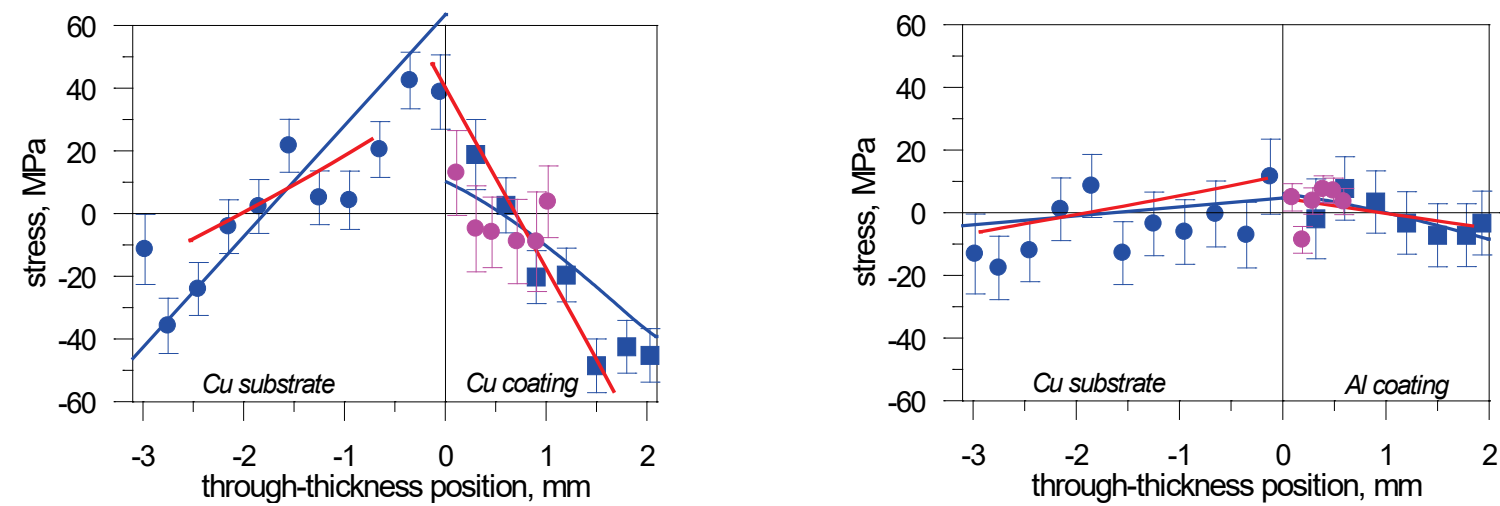

Fig. 5: The results of stress determination by the three methods for the two coating systems, $\mathrm{Cu} / \mathrm{Cu}$ (left) and Al/Cu (right). Neutron data are shown in blue symbols with Tsui \& Clyne model [10] (blue line) fitting to the datasets. X-ray data are shown as magenta symbols. The red line is for the slitting method results.

In the cases of neutrons and X-rays, the measurement and stress calculation procedures rely on average parameters leading to more robust results with better agreement.

\section{References}

[1] V. Luzin, A. Valarezo and S. Sampath, Through-

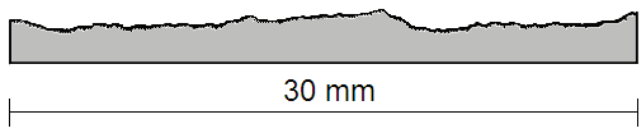

Fig. 6: Variation of the Al coating thickness profile: $t_{\min }=1.6 \mathrm{~mm}$, $t_{\max }=2.8 \mathrm{~mm}, t_{\text {ave }}=2.0 \mathrm{~mm}$.

thickness Residual Stress Measurement in Metal and Ceramic Spray Coatings by Neutron Diffraction, Mater. $\quad$ Sci. $\quad$ Forum $\quad 571-572 \quad$ (2008) 315-320. https://doi.org/10.4028/www.scientific.net/MSF.571-572.315

[2] V. Luzin, A. Vackel, A. Valarezo and S. Sampath, Neutron Through-Thickness Stress Measurements in Coatings with High Spatial Resolution, Mater. Sci. Forum 905 (2017) 165-173. https://doi.org/10.4028/www.scientific.net/MSF.905.165

[3] M.R. Hill, The Slitting Method, in: Practical Residual Stress Measurement Methods, John Wiley \& Sons, Ltd, 2013, pp. 89-108. https://doi.org/10.1002/9781118402832.ch4

[4] T. Gnaupel-Herold, Formalism for the determination of intermediate stress gradients using X$\begin{array}{llllll}\text { ray diffraction, } & \text { J. } & \text { Appl. } & \text { Crystallogr. } & 42 & \text { (2009) }\end{array}$ https://doi.org/10.1107/S0021889809004300

[5] T. Gnaeupel-Herold, T. Foecke, M. Iadicola and S. Banovic, in: SAE International, 2005.

[6] K.-D. Liss, B. Hunter, M. Hagen, T. Noakes and S. Kennedy, Echidna - the new highresolution powder diffractometer being built at OPAL, Physica B: Condensed Matter 385-386 Part 2 (2006) 1010-1012. https://doi.org/10.1016/j.physb.2006.05.322

[7] http://www.ncnr.nist.gov/instruments/darts/

[8] T. Gnaupel-Herold, P.C. Brand and H.J. Prask, Calculation of Single-Crystal Elastic Constants for Cubic Crystal Symmetry from Powder Diffraction Data, J. Appl. Crystallogr. 31 (1998) 929-935. https://doi.org/10.1107/S002188989800898X

[9] M. Law, O. Kirstein and V. Luzin, An assessment of the effect of cutting welded samples on residual stress measurements by chill modelling, J. Strain Anal. Eng. Des. 45 (2010) 567-573. https://doi.org/10.1177/030932471004500807

[10] Y.C. Tsui and T.W. Clyne, An analytical model for predicting residual stresses in progressively deposited coatings Part 1: Planar geometry, Thin Solid Films 306 (1997) 23-33. https://doi.org/10.1016/S0040-6090(97)00199-5 